
June 1943

\title{
A TUNGSTEN-IN-QUARTZ LAMP AND ITS APPLICATIONS IN PHOTOELECTRIC RADIOMETRY
}

\author{
By R. Stair and W. O. Smith*
}

\begin{abstract}
This paper gives constructional data relating to a tungsten-filament-in-quartz lamp and a discussion of its applications to precision filter radiometry. This lamp is adapted for use in the calibration of the spectral and total radiation sensitivity of phototubes. In its applications, it supplements the spectroradiometer for calibrating phototubes while employing the tubes with the associated filters used in measuring the radiation under investigation.

The spectral radiation output from such a lamp depends upon the temperature of the filament, the emissivity of tungsten, and the transmission of the fusedquartz envelope. A table of relative blackbody radiation intensities has been calculated for the temperature range $2,500^{\circ}$ to $2,900^{\circ} \mathrm{K}$ in the wavelength interval 2300 to 3500 angstroms.
\end{abstract}

\section{CONTENTS}

Introduction

II. Description of lamp _...

III. Spectral-energy distribution of the lamp_... 452

IV. Application of the lamp to the spectral calibration of phototubes_..... 455

V. Application of the lamp for the total radiation calibration of phototubes_ 458

VI. References_._._. 459

\section{INTRODUCTION}

The phototube has attained a place of great importance for making radiation measurements in the ultraviolet, visible, and near-infrared regions of the spectrum. The field of application is continually extending. Electronic devices for the amplification of the photoelectric current allow measurements of energies many thousand times smaller than are possible with the most sensitive thermopiles and galvanometers available. Reliable results are obtained by using stable amplifiers with microammeters or stable d'Arsonval galvanometers in cases where, because of mechanical vibrations, temperature changes, air currents, and the like, it is impossible to employ a sensitive thermopile-galvanometer radiometer.

Phototubes, however, have a selective response with respect to wavelength, which varies from tube to tube and also from point to point on the surface of the same electrode, both as to absolute intensity and as to wavelength range of sensitivity, even in tubes of the same type and process of manufacture. It is, therefore, necessary not only to calibrate individual tubes for the specific purpose to which they are to be applied, but the identical portion of the surface of the phototube that is to be used must be calibrated.

* Associate Physicist, Bureau of Plant Industry, U. S. Department of Agriculture. 
None of the existing procedures for the calibration of phototubes appears to be adequate. Accurate calibration has become an important problem in the field of photoelectric radiometry. Radiation from an ordinary Mazda CX lamp, used with filters, has been employed in the spectral calibration of some of the phototubes used for the measurement of short wavelength ultraviolet solar radiation and the determination of the amount of ozone in the stratosphere. [1]. ${ }^{1}$ More recently a tungsten-ribbon-filament lamp, with a fused-quartz window, has been used in the measurement of the spectral transmission of spectroradiometers [2]. The limitations of transmission of glass are removed, but since auxiliary diaphragms must be employed, in many cases it is possible to irradiate only a small part of the active surface of the phototube. The sensitivity of different parts of the active surface is known to vary considerably, and calibrations made for a portion of the active surface are not valid when the entire, or even another, portion of the active surface is used.

To eliminate the difficulties just mentioned, a tungsten-filament lamp, enclosed by a fused-quartz envelope, was constructed. Since this type of lamp appears to be a satisfactory standard source of continuous radiation, it will be fully described, and its properties and use discussed. Other types of tungsten-filament lamps with fused-quartz envelopes have been designed and used for other purposes $[5,17]$ with practical results.

\section{DESCRIPTION OF LAMP}

The lamp constructed is shown in figures 1 and $2 .^{2}$ It consists of an 8-mil straight filament of pure tungsten wire enclosed in a spherical fused-quartz envelope 4 inches in diameter. A straight round wire rather than a coiled filament was chosen to insure relatively even temperatures at all points on the wire. Black tungsten shields cover the filament ends and loops, as well as the molybdenum supporting hooks, and prevent radiation from these cooler areas of the filament reaching the receiver being calibrated. The filament consists of four evenly spaced "hairpin" loops arranged, in a plane, over an area approximately $3 / 4$ by $1 \frac{1 / 2}{2}$ inches. The blackened tungsten shields were placed inside the lamp for simplicity in the use of the lamp. It was realized that these shields would become heated and reradiate energy at long wavelengths. Since not more than 10 percent of the total energy radiated from the lamp filament can be absorbed by each shield, and since the surface of each shield is more than 10 times the total surface area of the filament, it follows that the total energy radiated per unit area of the shields is less than 1 percent of that for the filament. Hence the temperature reached by the shields cannot be very high, and therefore the spectral distribution of the radiation is limited to long wavelengths in the infrared, which do not excite available phototubes.

The lamp is filled with nitrogen at a pressure of 0.6 atmosphere. The filament was "flashed" in nitrogen, prior to sealing it in the fused-quartz envelope, at a temperature of about $3,000^{\circ} \mathrm{K}$ for 1 hour

\footnotetext{
1 Figures in brackets indicate the literature references at the end of this paper.

2 The advice and assistance of R. A. Nelson, of the Bureau of Plant Industry, in the construction of this lamp is gratefully acknowledged.
} 


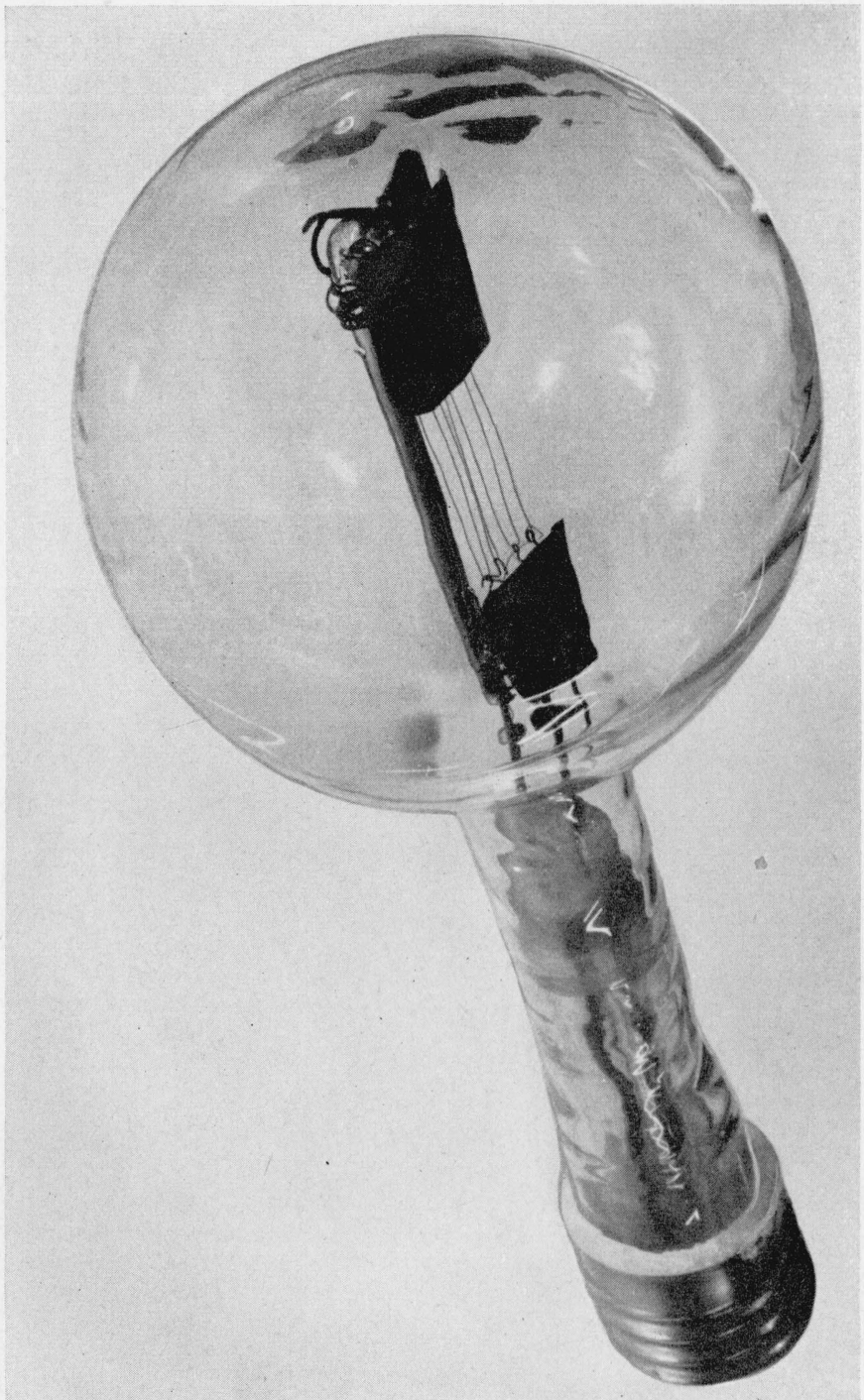

FIGURE 1.-Tungsten-in-quartz lamp. 
to free it of any impurities. It has been shown $[2,5]$ that different lots of tungsten agree in spectral emissivity, probably because at high temperatures most impurities are evaporated, leaving practically pure tungsten [5, 7]. To extend the useful life of such a lamp, it should not be operated at a temperature exceeding $2,800^{\circ} \mathrm{K}$ after flashing.

A lamp of this type, as shown by experience, should have a power input of about 500 watts to insure sufficient radiation output for the calibration of the relative spectral response of phototubes by the filter method, especially the types of tubes sensitive only to ultraviolet radiation. The problem of a source of power and its control must be considered when designing a lamp. It is convenient to have a lamp operating somewhat below 100 volts and at the same time requiring less than 10 amperes, so that it may be controlled with the common
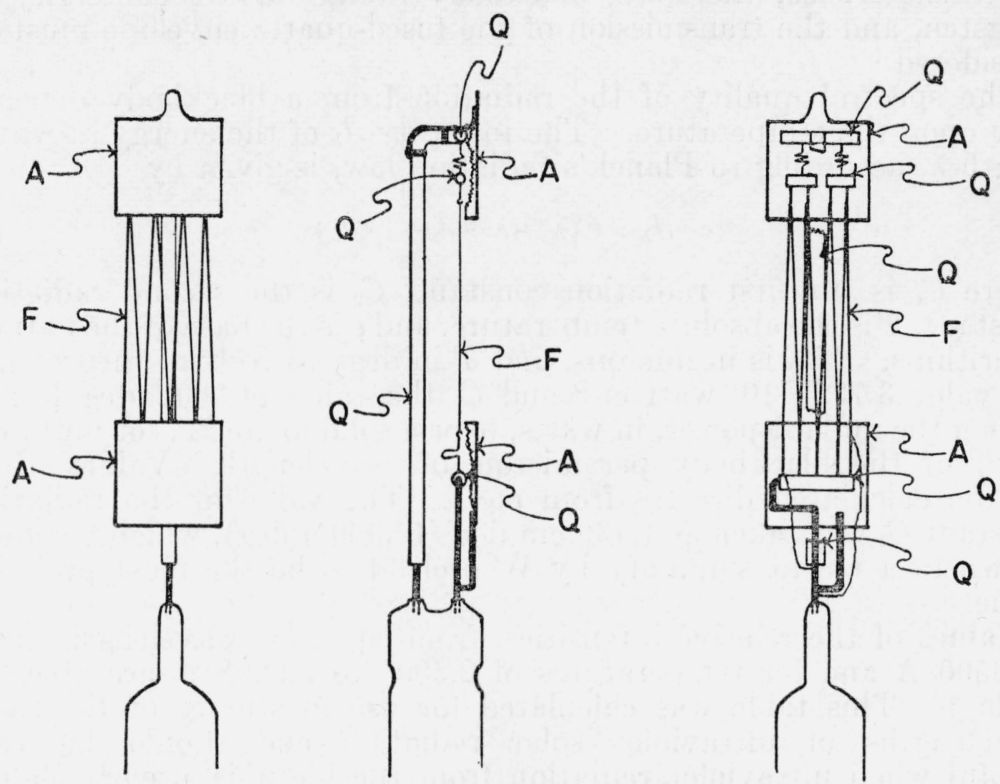

FIgURe 2.-Constructional details of the lamp.

A, Shields; F, filament; Q, quartz supports.

type of laboratory equipment. This is realized by using about 16 to 18 inches of 8-mil tungsten wire as a filament. A short ribbon filament operated at a low voltage and high current requires special control equipment.

The entire lamp envelope, except for the Pyrex press, is constructed of high quality fused quartz, since it has a high transmission throughout the region from below 2500 to above $20000 \mathrm{~A}$. This construction, together with shields which prevent radiation from the cooler ends and loops of the lamp filament reaching the phototube, eliminates the need of an additional diaphragm, or lens, between the lamp and tube under examination and thus the phototube is completely and uniformly irradiated with radiation of known spectral quality. Inhomogeneity and variations in the thickness of the quartz envelope render an image of the lamp filament distorted (see Fig. 1). This makes no difference, however, in the use of the lamp in the calibration 
of phototubes. If it is desired to use an image of the filament for some purpose, the lamp could be provided with a sealed-in window of polished fused quartz.

Finally, this lamp may be operated at any temperature from $2,000^{\circ}$ $\mathrm{K}$ to about $2,800^{\circ} \mathrm{K}$ without excessive depreciation of the tungsten filament or blackening of the lamp envelope.

\section{SPECTRAL-ENERGY DISTRIBUTION OF THE LAMP}

In applications such as the calibration of phototubes, an accurate knowledge of the distribution of the energy radiated from the lamp is required.' For the particular type of lamp considered in this paper, it is a function of the filament temperature, the emissivity of the material composing the filament, and the transmission of the envelope. For this purpose, therefore, blackbody radiation, the emissivity of tungsten, and the transmission of the fused-quartz envelope must be considered.

The spectral quality of the radiation from a blackbody depends only upon the temperature. The intensity $J_{\lambda}$ of the energy at wavelength $\lambda$, according to Planck's radiation law, is given by

$$
J_{\lambda}=C_{1} \lambda^{-5}\left(e^{C_{2} / \lambda} T-1\right)^{-1},
$$

where $C_{1}$ is the first radiation constant, $C_{2}$ is the second radiation constant, $T$ is the absolute temperature, and $e$ is the base of the natural logarithms. If $\lambda$ is in microns, and $T$ in degrees Kelvin, then $C_{1}$ has the value $3.732 \times 10^{4}$ watt $\mathrm{cm}^{2}$ and $C_{2}$ the value $14,360 \mu \mathrm{deg}$ [3]; $J_{\lambda}$ is then the radiant power, in watts, over a solid angle $2 \pi$, for unit area $\left(\mathrm{cm}^{2}\right)$ of the blackbody per micron of wavelength. Values of $J_{\lambda}$ can be calculated directly from eq 1 . The value of the radiation constant $C_{2}$ was taken as $1.436 \mathrm{~cm} \mathrm{deg}(14,360 \mu \mathrm{deg})$, which has been shown in a recent summary by Wensel [3] to be the most probable value.

Values of the relative intensities, from eq 1, for wavelengths 2300 to $3500 \mathrm{~A}$ and for temperatures of $2,500^{\circ}$ to $2,900^{\circ} \mathrm{K}$ are given in table 1. This table was calculated for use in studies of the short wavelengths of ultraviolet solar radiation and should be very helpful when ultraviolet radiation from the lamp is used. ${ }^{3}$ Values of $J_{\lambda}$ relative to that for $\lambda=0.3500$ micron are given for the temperature range $2,500^{\circ}$ to $2,900^{\circ} \mathrm{K}$ in $50^{\circ}$ increments. Wavelengths are given from 2300 to $3500 \mathrm{~A}$ in increments of $50 \mathrm{~A}$.

The values given in table 1 are $\left(J_{\lambda} / J_{0.3500}\right) \times\left(10^{4}\right)$; or what is equivalent, $J_{0.3500}$ has been set equal to 10,000 . The constant $C_{1}$, it is to be observed, is not used in the calculations, since these are relative values. Values of $e^{x}$ used to compute the data of these tables were taken from tables [11] recently published by the Work Projects Administration.

The values tabulated in table 1 are, in most cases, considered to be accurate to better than one in the final significant figure.

\footnotetext{
${ }^{3}$ Complete tables to 4 significant figures over the range $2,000^{\circ}$ to $3,100^{\circ} \mathrm{K}$, in $25^{\circ}$ steps, in the wavelength interval 2300 to 3500 angstroms, may be obtained upon application to the Nation 31 Bureau of Standards.
} 
TABLE 1.-Relative values of $J_{\lambda}$ based on a value of $J_{\lambda}$ at $\lambda=0.3500$ micron of 10,000

\begin{tabular}{|c|c|c|c|c|c|c|c|c|c|}
\hline \multirow{2}{*}{$\begin{array}{l}\text { Wave } \\
\text { lengths } \\
(\lambda)\end{array}$} & \multicolumn{9}{|c|}{ Blackbody temperatures } \\
\hline & $2,500^{\circ} \mathrm{K}$ & $2,550^{\circ} \mathrm{K}$ & $2,600^{\circ} \mathrm{K}$ & $2,650^{\circ} \mathrm{K}$ & $2,700^{\circ} \mathrm{K}$ & $2,750^{\circ} \mathrm{K}$ & $2,800^{\circ} \mathrm{K}$ & $2,850^{\circ} \mathrm{K}$ & $2,900^{\circ} \mathrm{K}$ \\
\hline$A$ & & & & & & & & & \\
\hline 2300 & 16 & 18 & 22 & 25 & 29 & 34 & 39 & 45 & 51 \\
\hline 2350 & 24 & 28 & 32 & 38 & 43 & 49 & 56 & 64 & 72 \\
\hline 2400 & 36 & 41 & 48 & 55 & 62 & 71 & 80 & 90 & 101 \\
\hline 2450 & 52 & 60 & 69 & 78 & 88 & 99 & 112 & 125 & 138 \\
\hline 2500 & 76 & 86 & 98 & 110 & 123 & 138 & 153 & 170 & 188 \\
\hline 2550 & 108 & 122 & 136 & 152 & 169 & 188 & 207 & 228 & 250 \\
\hline 2600 & 151 & 169 & 188 & 208 & 230 & 253 & 277 & 303 & 330 \\
\hline 2650 & 208 & 231 & 255 & 280 & 307 & 336 & 366 & 397 & 430 \\
\hline 2700 & 283 & 311 & 341 & 373 & 406 & 440 & 476 & 514 & 553 \\
\hline 2750 & 380 & 415 & 451 & 490 & 529 & 571 & 614 & 659 & 705 \\
\hline 2800 & 504 & 547 & 591 & 636 & 683 & 732 & 783 & 835 & 888 \\
\hline 2850 & 662 & 712 & 764 & 818 & 873 & 930 & 988 & 1048 & 1109 \\
\hline 2900 & 859 & 918 & 978 & 1040 & 1104 & 1169 & 1235 & 1303 & 1371 \\
\hline 2950 & 1103 & 1171 & 1240 & 1311 & 1383 & 1456 & 1530 & 1605 & 1681 \\
\hline 3000 & 1402 & 1480 & 1558 & 1637 & 1716 & 1798 & 1880 & 1962 & 2045 \\
\hline 3050 & 1767 & 1853 & 1940 & 2027 & 2114 & 2202 & 2291 & 2379 & 2468 \\
\hline 3100 & 2207 & 2301 & 2395 & 2488 & 2582 & 2676 & 2770 & 2863 & 2956 \\
\hline 3150 & 2734 & 2834 & 2953 & 3032 & 3130 & 3227 & 3324 & 3421 & 3516 \\
\hline 3200 & 3361 & 3464 & 3565 & 3666 & 3766 & 3865 & 3963 & 4059 & 4155 \\
\hline 3250 & 4099 & 4202 & 4303 & 4403 & 4501 & 4597 & 4693 & 4786 & 4878 \\
\hline 3300 & 4964 & 5062 & 5157 & 5250 & 5343 & 5434 & 5522 & & \\
\hline 3350 & 5970 & 6057 & 6141 & 6224 & 6304 & 6382 & 6459 & 6534 & 6607 \\
\hline 3400 & 7134 & 7201 & 7267 & 7332 & 7393 & 7454 & 7512 & 7569 & 7625 \\
\hline 3450 & 8472 & 8511 & 8549 & 8586 & 8622 & 8657 & 8690 & 8723 & 8754 \\
\hline 3500 & 10000 & 10000 & 10000 & 10000 & 10000 & 10000 & 10000 & 10000 & 10000 \\
\hline
\end{tabular}

Data $[12,13,14,15]$ are to be found elsewhere that contain similar blackbody calculations for longer wavelengths. The tables of Skogland [13], for example, list values of $\left(J_{\lambda} / J_{0.5900}\right.$ from 3200 to $7600 \mathrm{~A}$ for a temperature range of $2,000^{\circ} \mathrm{K}$ to $3,120^{\circ} \mathrm{K}$. A slightly different value of the second radiation constant $C_{2}$ is used in most published work, but a correction factor has been determined [14]. Where it is desired to calculate a specific value, a short method of calculation given by Coblentz [12] is useful.

The emissivity of tungsten has been determined by several workers $[4,5,6,7]$ for different temperatures. The data which appear to best represent the published values for the temperature range $2,700^{\circ}$ to $2,900^{\circ} \mathrm{K}$ are tabulated in table 2 . These values may be used in work of this kind throughout the range $2,500^{\circ}$ to $2,900^{\circ} \mathrm{K}$, since only relative values enter into the calculations.

As the transmission in the spectral region 2500 to $20000 \mathrm{~A}$ of fused quartz of the thickness (about $1 \mathrm{~mm}$ ) employed in this lamp is nearly uniform, no correction is necessary for most practical purposes. The transmission of the fused-quartz envelope of the lamp must be taken into consideration, however, when a phototube has its major response in the short wavelengths, for example, a tungsten or tantalum phototube in a quartz or special ultraviolet transmitting glass envelope. 
TABLE 2.-An example of the application of the tungsten-in-quartz lamp in the determination of the spectral response of a phototube

[The spectral-response data (col. 5) are adjusted until the observed and calculated filter transmissions are in close agreement]

\begin{tabular}{|c|c|c|c|c|c|c|c|c|c|c|c|c|c|}
\hline \multirow[b]{2}{*}{$\begin{array}{l}\text { Wave- } \\
\text { length }\end{array}$} & \multirow[b]{2}{*}{$\begin{array}{l}\text { Rela- } \\
\text { tive } \\
\text { radia- } \\
\text { tion } \\
\text { from } \\
\text { black } \\
\text { body } \\
\text { at } \\
2,737^{\circ} \\
\mathbf{K}\end{array}$} & \multirow[b]{2}{*}{$\begin{array}{l}\text { Emis- } \\
\text { sivity } \\
\text { factor } \\
\text { for } \\
\text { tung- } \\
\text { sten }\end{array}$} & \multirow{2}{*}{$\begin{array}{l}\text { Rela- } \\
\text { tive } \\
\text { radia- } \\
\text { tion } \\
\text { from } \\
\text { tung- } \\
\text { sten } \\
\text { at } \\
2,737^{\circ} \\
\mathrm{K} \\
\text { (col. } 2 \\
\times \\
\text { col. } 3 \text { ) }\end{array}$} & \multirow[b]{2}{*}{$\begin{array}{c}\text { Rela- } \\
\text { tive } \\
\text { re- } \\
\text { sponse } \\
\text { of } \\
\text { tita- } \\
\text { nium } \\
\text { photo- } \\
\text { tube } \\
A\end{array}$} & \multicolumn{4}{|c|}{ Filter transmissions } & \multirow{2}{*}{$\begin{array}{c}\text { Rela- } \\
\text { tive } \\
\text { radia- } \\
\text { tion } \\
\text { from } \\
\text { tung- } \\
\text { sten } \\
\text { times } \\
\text { rela- } \\
\text { tive } \\
\text { re- } \\
\text { sponse } \\
\text { of } \\
\text { photo- } \\
\text { tube } \\
\text { (col. } \\
4 \times \text { col. } \\
5 \text { ) }\end{array}$} & \multicolumn{4}{|c|}{$\begin{array}{l}\text { Relative radiation from } \\
\text { tungsten times relative } \\
\text { response of phototube } \\
\text { times filter transmissions }\end{array}$} \\
\hline & & & & & CX-D & $\mathrm{Ni}$ & $\mathrm{Ba}-1$ & $\mathrm{Ba}-3$ & & Cx-D & $\mathrm{Ni}$ & Ba-1 & $\mathrm{Ba}-3$ \\
\hline 1 & 2 & 3 & 4 & 5 & 6 & 7 & 8 & 9 & 10 & 11 & 12 & 13 & 14 \\
\hline$\underset{2560}{A}$ & & & & & $\%$ & $\%$ & $\%$ & $\%$ & & & & & \\
\hline 2580 & 22.1 & $\begin{array}{r}0.595 \\
.394\end{array}$ & 8.71 & $\begin{array}{l}0 \\
8\end{array}$ & & 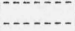 & 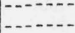 & - n...... & $\begin{array}{r}0.5 \\
.7\end{array}$ & & & & \\
\hline 2600 & 24.7 & .395 & 9.76 & 10.5 & & - & & & 1.0 & & & & \\
\hline 2620 & 27.7 & .397 & 11.00 & 13 & & & & & 1. 4 & & & & (n) \\
\hline 2640 & 31. 1 & .398 & 12. 38 & 16 & $\ldots$ & & & $-\ldots$ & 2.0 & &.- & $\ldots$ & $\ldots$ \\
\hline 2660 & 35.0 & .399 & 13.96 & 19.5 & -1 & -- & ... & $-\ldots$ & 2.7 & & $\ldots$ & -1 & -..... \\
\hline 2680 & 39.0 & .400 & 15. 6 & 23 & 0.6 & $\ldots$ & ... & -1 & 3. 6 & & $\ldots$ & $\ldots \ldots$ & $\ldots$ \\
\hline 2700 & 43. 2 & .401 & 17.3 & & 1.7 & - & $\ldots$ & - & 4. 8 & 0.1 & 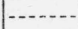 & - & ....... \\
\hline 2720 & 48. 0 & .402 & 19.3 & & 3.0 & - & $\ldots$ & $\cdots$ & 6. 6 & .2 & $\ldots$ & $\ldots$ & $\ldots$ \\
\hline $\begin{array}{l}2740 \\
2760\end{array}$ & 53.4 & .403 & 21.5 & 41 & 4. 3 & - & -1 & $\ldots$ & 8.8 & .4 & $\ldots \ldots$ & $\ldots \ldots$ & $-\ldots$ \\
\hline $\begin{array}{l}2760 \\
2780\end{array}$ & 59.3 & .405 & $\begin{array}{l}24.0 \\
26.6\end{array}$ & $\begin{array}{l}47.5 \\
53.5\end{array}$ & $\begin{array}{l}6.2 \\
8.2\end{array}$ & - n & . & $\cdots$ & 11. 4 & .7 & $\ldots$ & 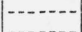 & $-\cdots$ \\
\hline $\begin{array}{l}2780 \\
2800\end{array}$ & $\begin{array}{l}65.5 \\
72.0\end{array}$ & $\begin{array}{l}.406 \\
.407\end{array}$ & $\begin{array}{l}26.6 \\
29.3\end{array}$ & $\begin{array}{l}53 . \\
60\end{array}$ & $\begin{array}{l}8.2 \\
11\end{array}$ & & & & $\begin{array}{l}14 . \\
17 .\end{array}$ & $\begin{array}{l}1.2 \\
1.9\end{array}$ & - & $\begin{array}{ll}-1 \\
-1\end{array}$ & 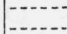 \\
\hline 2820 & 79. & .408 & 32. & & 14. 5 & & & & 21. & 3.1 & 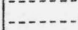 & - & - \\
\hline 2840 & 87.0 & .410 & 35. & 71 & 18.5 & & & & 25. & 4. 7 & & $\ldots$ & $\ldots$ \\
\hline 2860 & 95.0 & .411 & 39.0 & 76 & 23 & 0.3 & & & 29.6 & 6.8 & 0.1 & & $\ldots$ \\
\hline 2880 & 103. 0 & .412 & 42.4 & 79 & 28 & 1.7 & & $\ldots$ & 35.5 & 9.4 & .6 & $\ldots \ldots$ & $\ldots$ \\
\hline 2900 & 115. & .413 & 47.6 & 79.5 & 33 & 3.3 & & & 37.8 & 12. & 1. 2 &.- & \\
\hline 2920 & 125 & .415 & 51. & 7 & 3 & 5.3 & & & 41. & 15 & 2. 2 & & - \\
\hline 2940 & 137 & .417 & 57. & & 43 & 7. 6 & & & 44. & 19 & 3.4 & - & $-1-2$ \\
\hline 2960 & 150 & .419 & 62. & 74.5 & 47.5 & 10.0 & & & 46. & 22 & 4.7 & $\ldots$ & $\ldots$ \\
\hline 2980 & 163 & .420 & 68.5 & 70.5 & 52 & 13. 2 & & & 48. & 25. & 6.4 & $\ldots . .$. & $\ldots$ \\
\hline 3000 & 178 & .422 & 75.1 & 66 & 56.3 & 16.5 & & & 49.6 & 27. & 8.2 & & $\ldots$ \\
\hline 3020 & 193 & .423 & 81. & 1.5 & 60.2 & 21 & 0.3 & & & 30 & 10. & 0.2 & $\ldots$ \\
\hline 3040 & 211 & .424 & 89. & & 6 & & 1. & & 51. & 33 & 13. & .7 & $\ldots$ \\
\hline 3060 & 229 & .426 & 97. & 52.5 & 66. & 31.5 & 3. & & & & 16. & 1.5 & 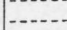 \\
\hline 3080 & 248 & .427 & 105. & 48.5 & 69.5 & 36.5 & 5. & & 51. & 35. & 18. & 2.8 & $\ldots$ \\
\hline 3100 & 265 & .428 & 113. & & 72.3 & 41. 8 & 9.3 & & 49. & 36. & 20.9 & 4. 6 & \\
\hline 3120 & 289 & .429 & 124.0 & 40 & 74.8 & 46.5 & 14.5 & 0.1 & & 37.1 & 23.1 & 7.2 & 0.05 \\
\hline 3140 & 311 & .430 & 133.8 & 36.5 & 76.8 & 51.5 & 21.5 & & & & & 10. & .3 \\
\hline & 335 & .43 & 144 & & & & & 2. & & & & 12 & 1. 1 \\
\hline & & .432 & 155. & 28.5 & & & 34. & 5 & & & 26 . & 15. & 2. 22 \\
\hline 320 & 384 & .433 & 166. & 24.5 & 81. 3 & 64 & & 8 & & 33. & 26.1 & 16.7 & 3. 26 \\
\hline 3220 & 412 & .434 & 178. & & 82.4 & 67 & 47 & 12 & 37. & 31. & 25.2 & 17.7 & 4. 51 \\
\hline 3240 & 442 & .435 & 192.3 & 17 & 83.4 & 70 & 53.5 & 18 & 32. & 27. & 22 . & 17. & 5.8 \\
\hline & 47 & .436 & 206. & 13.5 & 84.4 & 73 & & 2 & & & 20. & 16. & 6.9 \\
\hline & 50 & .437 & 221. & 10 & & 75.8 & & 3 & 22 . & 18. & 16.8 & 14. & 7.07 \\
\hline 3300 & 54 & 438 & 237. & 7.3 & 85.5 & 77.8 & 68 & 39 & 17. & 14. & 13.5 & 11.8 & 6.75 \\
\hline 3320 & 580 & 439 & 254.7 & 4.6 & 86.3 & 79.5 & 71.5 & 45.5 & 11. & 10. 1 & 9.3 & 8. 4 & 5. 33 \\
\hline 3340 & 620 & .440 & 272.8 & 2.5 & 86.7 & 81 & 74.5 & 51 & 6. & 5. 9 & 5.5 & 5. 1 & 3.48 \\
\hline 3360 & 662 & .441 & 292.0 & 1.3 & 87.3 & 82.5 & 77 & 56 & 3. & 3. & 3. & & 2.13 \\
\hline & 703 & .442 & 300.8 & 0.6 & & 83.6 & & 60 & 1. & 1. & 1. 4 & 1. & 0.99 \\
\hline 3400 & 744 & .433 & 329.7 & .3 & 88.3 & 84.5 & 80.5 & 64 & 0.9 & 0.8 & 0.8 & 0.7 & .59 \\
\hline \multirow{3}{*}{\multicolumn{9}{|c|}{$\begin{array}{l}\text { Total } \\
\text { Calculated percentage transmission } \\
\text { Observed percentage transmission }\end{array}$}} & 1100.1 & 636.8 & 352.3 & 168. 3 & 50.78 \\
\hline & & & & & & & & & - & 57.9 & 32.0 & 15. 3 & 4. 61 \\
\hline & & & & & & & & & & 59.0 & 31.9 & 14.8 & 5.83 \\
\hline
\end{tabular}


The relative spectral emission from the lamp, for a given temperature, is the product of the relative blackbody radiation intensities, the emissivity of the tungsten filament (each for the given temperature), and the transmission of the fused-quartz lamp envelope. In table 2 , the blackbody radiation and the emissivity values for a temperature of $2,737^{\circ} \mathrm{K}$ (which was the mean true temperature of the lamp filament in this case) are given, together with their product. The transmission of the quartz envelope has been neglected in this case, and for all practical purposes this product represents the relative spectral emission of the lamp for that temperature, since the transmission of the fused-quartz envelope varies but slightly throughout the spectral range in which this phototube is sensitive.

\section{APPLICATION OF THE LAMP TO THE SPECTRAL CALIBRATION OF PHOTOTUBES}

The use of a continuous spectrum source in conjunction with filters to supplement the spectroradiometer in the determination of the spectral response of phototubes was discussed in detail in a previous publication [1]. Since the tungsten-in-quartz lamp is calibrated by a single measurement of the mean filament temperature, its spectral emission is readily determined and kept constant by controlling the voltage. As the result of heat conduction along the filament to the supporting elements within the lamp, and because of variations in filament thickness and absorption of radiation from other elements of the filament assembly, there is always a certain amount of variation in the temperature of different sections of the filament. Hence it becomes necessary to obtain a mean, or average, value for the filament temperature. This may be obtained by different methods. but for the purposes for which this lamp is to be employed it is probably most practically obtained by observing the color temperature ${ }^{4}$ of the total visible radiation from the lamp and reducing this value to true temperature $[6,16]$.

Some calculations, in which the published values of emissivity were used [5], on filament sections having assumed differences in temperature of the magnitude for the type of lamp described in this paper, indicate that mean true temperature values obtained from colortemperature measurements also accurately apply in the ultraviolet spectral range 2500 to $3500 \mathrm{~A}$.

The authors have considered the use of a ribbon instead of a roundwire filament in order to reduce the end and loop-cooling effects, but because of difficulties in keeping different sections of the filament in the same plane, it appears that the round wire is more desirable from the standpoint of the stability of the radiation received by the radiometer. The end cooling effects are reduced to a low value if the shields cover $1 / 4$ to $1 / 2$ inch of the filament ends and loops. The temperature variation between different sections of the filament could be reduced by a wider spacing of the filament loops.

Since it is usually impossible to irradiate evenly the entire surface of the cathode of the phototube in the spectroradiometric method of calibration of the relative spectral response, the response curve obtained applies only to the portion of the phototube irradiated, and for

${ }^{4}$ These color temperature measurements were made by Deane B. Judd, of the National Bureau of Standards. 
accurate work it becomes necessary to correct this curve so that it will apply to the entire phototube surface as used in practice.

Phototubes, as pointed out in the previous paper [1], often possess a long wavelength "tail" in their relative spectral-response curves which is not detected in the spectroradiometric calibration of the relative spectral response, but which in the use of the tubes may produce very large errors, especially if the source of radiation has a relatively high emission in this spectral region. Not only is the presence of a long wavelength "tail" to the spectral-response curve of a phototube simply detected by means of this lamp in conjunction with a set of calibrated filters, but the magnitude of its effect may be closely evaluated, so that the phototube may be used in precision work.

Since, as illustrated by the data of tables 3 and 4 , the true photoelectric-response curve may, for all practical purposes, be much different from the spectroradiometrically observed curve, especially near the long wavelength limit of the tube, extra precautions in the use of double monochromators, etc., in the determination of phototube response curves would be useless effort unless the data were supplemented by other means, for example, by observations using a tungsten lamp and calibrated filters. The use of a tungsten lamp and calibrated filters to supplement the results obtained appears to be required with even the best of spectroradiometers if high precision is to result. It would be very much better to use monochromator data, although it may not be of high accuracy, supplemented by lamp and filter measurements, than to rely solely on the best double monochromator.

TABLE 3.-Results of comparative tests of two phototubes for agreement beiween calculated and observed filter transmissions

[The data for tube $A$ were taken from table 2, and show close agreement between observed and calculated transmissions. The data for tube $B$ show a large discrepancy, although the response curve was obtained with great care on a good spectroradiometer. The calculations marked I were made upon the basis of a smooth spectral-response curve drawn through the spectroradiometrically observed points. Calculations II were made upon an adjusted curve (see table 4). Tube B appeared to have a slight amount of "fatigue," which probably accounts for part of the discrepancy between the calculated and observed filter transmissions]

\begin{tabular}{|c|c|c|c|c|c|c|c|c|}
\hline \multirow{2}{*}{ Filter } & \multicolumn{2}{|c|}{$\begin{array}{l}\text { Phototube } A \text { (no } \\
\text { filter) }\end{array}$} & \multicolumn{3}{|c|}{ Phototube $B$ (no filter) } & \multicolumn{3}{|c|}{ Phototube $B$ (Nillite filter) } \\
\hline & Obs. & Calc. I & Obs. & Calc. I & Calc. II & Obs. & Calc. I & Calc. II \\
\hline $\begin{array}{l}\mathrm{Cx}-\mathrm{D} \\
\mathrm{Ni} \\
\mathrm{Ba}-1 \\
\mathrm{Ba}-3\end{array}$ & $\begin{array}{r}59.0 \\
31.9 \\
14.8 \\
5.8\end{array}$ & $\begin{array}{r}57.9 \\
32.0 \\
15.3 \\
4.6\end{array}$ & $\begin{array}{r}38.2 \\
19.0 \\
8.8 \\
3.3\end{array}$ & $\begin{array}{r}24.9 \\
6.7 \\
1.2 \\
0.1\end{array}$ & $\begin{array}{r}34.0 \\
15.4 \\
7.6 \\
3.1\end{array}$ & $\begin{array}{l}75.6 \\
53.8 \\
31.3 \\
13.4\end{array}$ & $\begin{array}{r}63.5 \\
31.4 \\
9.1 \\
1.0\end{array}$ & $\begin{array}{l}75.1 \\
53.8 \\
34.8 \\
15.6\end{array}$ \\
\hline
\end{tabular}


TABLE 4.-Adjustment of phototube spectral response

[The values indicate the adjustment in the relative spectral response of phototube $B$ required to give filter transmissions which approximate the observed values when using the tungsten-in-quartz lamp and calibrated filters, see tables 2 and 3]

\begin{tabular}{|c|c|c|}
\hline Wavelength & $\begin{array}{l}\text { Spectroradio- } \\
\text { metrically } \\
\text { observed } \\
\text { response, } \\
\text { curve I }\end{array}$ & $\begin{array}{l}\text { Adjusted } \\
\text { response, } \\
\text { curve II }\end{array}$ \\
\hline$A$ & & \\
\hline 2600 & 133 & 108 \\
\hline 2640 & 121 & 103 \\
\hline 2680 & 110 & 98 \\
\hline 2720 & 97 & 90 \\
\hline 2760 & 85 & 83 \\
\hline 2800 & 72 & 72 \\
\hline 2840 & 60 & 60 \\
\hline $\begin{array}{l}2880 \\
2920\end{array}$ & $\begin{array}{l}48 \\
37\end{array}$ & $\begin{array}{l}48 \\
37\end{array}$ \\
\hline 2960 & 26.5 & 26.5 \\
\hline 3000 & 18 & 18 \\
\hline 3040 & 12 & 13 \\
\hline 3080 & 7 & 9.5 \\
\hline $\begin{array}{l}3120 \\
3160\end{array}$ & 3.5 & 7 \\
\hline $\begin{array}{l}0100 \\
3200\end{array}$ & 0.8 & 4 \\
\hline 3240 & .2 & 3 \\
\hline 3280 & . & 2 \\
\hline $\begin{array}{l}3320 \\
3360\end{array}$ & - & 1. 5 \\
\hline 3400 & & 0.5 \\
\hline
\end{tabular}

By measuring the integrated transmissions of a set of calibrated filters with this lamp as a source, and by calculating the integrated transmissions of the same filters from a knowledge of their spectral transmission, the spectral-energy emission of the lamp, and the spectral response of the phototube (based upon an arbitrary curve drawn through the values for the wavelengths at which the response was determined spectroradiometrically), the shape of the phototube response may be altered until the observed and calculated transmissions are in agreement.

For all practical purposes, the number of filters can be increased by $(n-1)$ by using combinations of each filter with the one having the nearest long (or short) wavelength cutoff. In certain cases more remote combinations can also be employed to advantage. This is especially true where filters having bands of selective absorption are employed in evaluating radiation over a long wavelength range of the spectrum. The particular problem in hand, together with the characteristics of the available filters, will determine the most useful combinations. A great amount of labor may be saved by using a combination filter rather than calibrating a new one where the combination gives the desired spectral transmission.

In this method of determining the relative spectral response of a phototube the entire electrode of the cell is fully and evenly irradiated, so that any local variations in the relative spectral response are averaged into the final response curve for the cell as used in practice. This is important, since in the manufacture of cells a uniform cathode surface is rarely obtained. Differences in the thickness of the sensitive layer or the presence of impurities modify the relative spectral response of one area of the receiving surface relative to another adjoining area in the same phototube.

$524586-43-3$ 
Having obtained a careful evaluation of the spectral photoelectric response and the transmissions of the available filters, the problem of the measurement of ultraviolet radiation from a given source requires a certain amount of information concerning the spectral quality of the source under investigation. If the source is a temperature radiator, as, for example, an incandescent-filament lamp of unknown filament temperature, a smooth curve may be assumed and adjusted to its true relative spectral value through a set of observations and calculations on the filter transmissions. For a discontinuous source, as, for example, a metallic arc, the wavelength and a knowledge of the relative intensity of the emission lines are necessary. In the case of a source of intermediate type, as a carbon arc or the sun, where there are emission bands with intervening regions of low intensity, a knowledge of the shape of the emission curve is essential.

In the calculations on the sun $[1,8,9]$ a smooth curve was assumed (because the true shape of the curve was unknown), and the results are given in terms of the equivalent radiation for a definite wavelength interval on the basis of that assumption. This has a shortcoming, in that it is impossible to evaluate accurately the intensity of the radiation in any definite wavelength interval, since ultraviolet solar radiation is not distributed according to a smooth curve but is concentrated in definite bands with relatively low intensities at intermediate wavelengths. The accuracy of any evaluation of this type will therefore depend upon the wavelength interval chosen and upon the range of spectral sensitivity of the phototube employed.

Therefore, it at once becomes obvious that to evaluate ultraviolet solar radiation accurately in a definite wavelength interval an approximate shape of the true spectral solar radjation emission curve should be obtained. Since it is impossible to obtain this curve by means of an ordinary spectroradiometer (because of scattering within the instrument), it would be a valuable contribution in this field for someone having available a quartz lens and prism double monochromator to make this determination for (different air masses) several altitudes of the sun. Photoelectric filter radiometry in solar radiation studies will, with this accomplishment, be put on a practical scientific basis.

\section{APPLICATION OF THE LAMP FOR THE TOTAL RADIATION CALIBRATION OF PHOTOTUBES}

A practical method of using a standard quartz mercury-arc lamp for calibrating the total response of phototubes, together with the associated amplifier or other indicating or recording instrument, has been described in detail elsewhere $[8,9,10]$. The herein-described tungsten-filament-in-quartz lamp may be used in a similar manner and may have advantages in some cases over the mercury lamp. The radiation intensity is more constant, both in relative spectral quality and in total intensity, and its operation requires less care in the control of room temperature and circulating air currents. Furthermore, since the tungsten lamp emits radiation throughout the range of sensitivity of the phototube, the calibration applies to the total integrated curve rather than to a few isolated wavelengths. If the cell is employed in work involving a more or less continuous spectrum, or one which is at least different from the mercury arc, the advantage of using this type of spectrum in the calibration is obvious. 
Since the lamp envelope absorbs the long infrared radiation emitted by the filament and emits some infrared radiation, of very long wavelength, characteristic of the temperature of the quartz envelope, the lamp is more easily calibrated, for absolute radiation intensity per unit wavelength at a fixed position relative to the lamp, by employing a 1-centimeter water cell over the thermopile. Phototubes are insensitive to this infrared radiation, and a water cell is not required in the use of the lamp with them.

If the sensitivity of the phototube is confined to a narrow range of the spectrum, as in the case of the two titanium tubes referred to above (see tables 2 and 3), additional filters may be employed to evaluate the limited range of the spectrum of the lamp radiation covering that to which a particular phototube is sensitive. Since the relative emissivity of tungsten is known none too well over the total spectral range from 2300 to $15000 \mathrm{~A}$, it is obviously an advantage to limit the range of calibration of the lamp to the spectral range over which the phototube responds.

The authors thank Leonardo Testa, of the Bureau of Plant Industry, for the glass and quartz work required in the construction of the lamp; also E. S. Shipley and Joseph F. Mullins, of the Bureau of Plant Industry, for constructing the filament, shields, and mountings of the lamp.

\section{REFERENCES}

[1] R. Stair and I. F. Hand, Methods and results of ozone measurements over Mount Evans, Colo., Monthly Weather Rev. 67, 331 (1939).

[2] R. Stair and W. W. Coblentz, Spectral energy distribulion of the standard comparison lawp used in evaluating flash spectrum of the solar eclipse of 1940, Nat. Geog. Soc., Contr. Tech. Papers, Solar Eclipse Series No. 2, p. 48 (1942).

[3] H. T. Wensel, International Temperature Scale and some related physical constants, J. Research NBS 22, 375 (1939) RP1189.

[4] F. Hoffman and H. Willenberg, Physik. Z. 35, 1, 711 (1934).

[5] H. C. Hamaker, Reflectivity and Emissivity of Tungsten, Inaug. Diss Utrecht, Holland (1934).

[6] W. E. Forsythe and A. G. Worthing, Astrophys. J. 61, 146 (1925).

[7] L. S. Ornstein, Physica 3, 561 (1936).

[8] W. W. Coblentz and R. Stair, J. Research NBS 16, 315 (1936) RP877; BS J. Research 6, 951 (1931) RP318; J. Research NBS 15, 123 (1935) RP816.

[9] R. Stair and W. W. Coblentz, J. Research NBS 20, 185 (1938) RP1075.

[10] R. Stair and I. F. Hand, Bul. Am. Met. Soc. 22, 259 (1941).

[11] Federal Works Agency, Work Projects Administration, Table of the Exponential Function $e^{x}$ (1939).

[12] W. W. Coblentz, BS Sci. Pap. 15, 617 (1920) S360.

[13] J. F. Skogland, Misc. Pub. BS M86 (1929).

[14] Parry Moon, Table of Planck's Function from $3,500^{\circ}$ to $8,000^{\circ} \mathrm{K}$ (Mass. Inst. of Tech., Cambridge, Mass.)

[15] M. Katherine Frehafer and Chester L. Snow, Misc. Pub. BS M56 (1925).

[16] H. T. Wensel, D. B. Judd and Wm. F. Roeser, Establishment of a scale of color temperature, BS J. Research 12, 527 (1934) RP677.

[17] John Strong, Procedures in Experimental Physics (Prentice-Hall, Inc., New York, N. Y., 1942).

Washington, February 25, 1943. 